\title{
Analysis of Heterogeneous Indian Auto Component Replacement Suppliers: A Perspective On Simultaneous Entry
}

\author{
Nimit Jain \\ Lead Data Scientist, Novartis Services Inc. \\ 6201 South Fwy, Fort Worth, TX 76134 \\ Email:nimitj@iimahd.ernet.in \\ Suman Niranjan \\ Associate Professor of Operations Management, 209 Jordan Bldg., \\ College of Business Administration, Savannah State University, Savannah, USA \\ Email: niranjans@savannahstate.edu (Corresponding Author)
}

\begin{abstract}
Competition on price alone is no longer sustainable. Increasingly, firms are competing on multiple dimensions such as service quality, performance quality, process technology, and product variety. In this paper we study how firms might make some of these decisions in a high margin and fragmented Indian auto component replacement market. Using game theoretic principles, we analyze the replacement market when the non-OES (original equipment suppliers, national/regional) makes decisions in presence of an OES. Along with this, we analyze the market when the OES and non-OES enter simultaneously and make decisions based on their risk appetite. Our results indicate that the investment in a more capable technology doesn't necessarily lead to higher optimal price. More capable technology decreases the marginal cost which allows the firm to decrease the price but more capable technology also increases the share of market demand which allows the firm to price higher.
\end{abstract}

Keywords: indian auto component replacement, game theory, original equipment suppliers, maxmin, maxmax, price, quality, technology

\section{INTRODUCTION}

There are more than 5000 firms in Indian auto component replacement market (ACMA 2014). Increasing number of auto component manufacturing firms are entering into a $\$ 40$ Billion (Make in India, 2015), and poised to cross $\$ 113$ Billion by 2020 (Shivaraman, 2015), especially because Indian auto replacement market has low entry barriers, high margins and high demand. High demand of components is a result of tendency of customers to keep the same vehicle longer and poor conditions of Indian roads. The demand for replacement components is expected to grow at a steady pace of 7 percent annually which is relatively quite high in the context of developing country. Additionally exports of auto components have also seen a significant boost at an annual growth rate of $17 \%$ during 2008-13, achieving $\$ 9.7$ Billion in 2012-13. We observe that there are three types of firms in the replacement market. First type of firm is a supplier of components to original equipment $(\mathrm{OE})$, and replacement markets. We call this supplier an original equipment supplier (OES). Then we observe non-OES suppliers supplying components in the domestic replacement market. Depending on the market coverage they are classified as national and regional players. The distribution network for non-OES national firms spans across India, but non-OES regional firms sell their products near to their manufacturing plant (Chandra and Jain, 2009).

The diversity in components is observed in terms of price, warranty and core product characteristics. Typically, on an average twelve firms compete for same category of component, with OES, non-OES national and non-OES regional firms present in the proportion of $3: 1: 2$. Customers, at the same time are heterogeneous in their preferences among the variety of options available to them. They choose a particular component by trading off between price and, warranty and other product characteristics, which in turn is dependent on their income, type and age of the vehicle owned. Thus, the demand for an auto component firm is influenced by their decision on price and product offering.

Entry of a new entrant in the auto component replacement market demands crucial strategic decisions on product, which are critical for its sustainability. These decisions are of prime importance to smaller regional nonOES firms which faces a tough competition from OES products because of their better brand image. At the same time, for a firm who is launching variety of products, it also needs to decide on the optimal sequence of launching multiple products. Currently, firms are seen to take such decisions on ad-hoc basis instead of using any analytical tool. Though, the existing decision process doesn't necessarily result in a sub optimal solution, there is a need for standardized decision making tool which could help firms to adjust to dynamic situations in the market. While launching a new product, a firm needs to consider the threat from not only existing products but also from products to be launched in future. Also, a firm needs to incorporate the uncertainty in preferences of customers. Hence, we study 
the problem of a new entrant in the auto component replacement market, who launches a new product in different competitive settings.

In analyzing the situation of a new product launch, we first assume that a firm decides on process technology and performance quality prior to its decision on price. This sequence of making decisions is plausible because strategic nature of investments in technology and performance quality make the frequent alterations in product offering difficult as compared to alteration in price. The choice of process technology, idly has an effect on both, the performance and conformance quality of a product. But conformance quality is also influenced by the level skills of workers and shop floor practices, and performance quality is also influenced by the type of raw material used to manufacture the product. We model considering that process technology completely determines the conformance quality and type of raw material completely determines the performance quality of a component. As the options of technology and raw material available to manufacturer are finite and limited, we model these as discrete variables. We incorporate the demand side effects of product offering decision by extending the linear demand function put forth by Dixit (1979) such that the demand for a firm's product increases with the increase in its own performance quality and decreases with the increase in competitor's performance quality. Same behavior holds for decision on technology. Lastly, we operationalize the idea put forth by Juran (1951) on the effect of choice of conformance and performance quality on the cost of the final product.

A new entering firm encounters various competitive settings while launching a new product because of innumerable auto component parts, the complexity in the manufacturing process, the cost and knowledge required for entry to the market. It is observed that usually the OES is the first entrant in the market, non-OES firms enter later. But OES and non-OES firms are also observed to enter simultaneously. One reason for non-OES firm to enter the market along with the OES could be when the non-OES is aware of the product design specifications of the component of a new vehicle through the knowledge derived from being present in international markets. While launching a new product simultaneously a firm faces the difficult task of anticipating its competitor moves. In such circumstances they make decisions either on the basis of private information on competitor or by considering the best and worst case scenarios.

In this paper, we consider the case when the OES is present in the market and is an established player. Non-OES enters the market and has to make decisions on product offering and price. OES doesn't react to the entry of the non-OES. This situation is observed in the replacement market when OES decisions on product are governed by their prime customers- OEM. Large volumes, technological support and better export opportunity creates incentive for the OES to partner with OEM in deciding the product offering and price. We also vary this entry situation for the non-OES firm, when the OES and non-OES firms launch their products simultaneously and make product offering and pricing decisions competitively. The non-OES is observed to enter the market along with the OES firm, when it can correctly anticipate the timing of entry of the $\mathrm{OES}$, and size of the market for a replacement component is large. The product offering includes decision on performance quality and process technology. The performance quality would define the most important operating characteristic of a component and process technology would primarily affect the internal and external defect rate of a component. With this understanding of the market, we find the linkages between competitors, their operating environment and their choices. Specifically, we address the following questions: (i) How should a new entrant, that is, non-OES optimally position its product, with respect to price ( $p)$, performance quality $(q)$ and

technology $(t)$, in a competitive setting when the OES firm already exists?, (ii) How should two firms, that is, OES and non-OES position their products with respect to price $(p)$,

performance quality $(q)$ and technology $(t)$ when they enter simultaneously in a competitive setting?

We find the following important managerial implications when non-OES enters the market with existing OES already established player: (i) depending on the change in demand at optimal price non-OES firm will decide on the level of quality, tradeoff between customers lost due to increase in optimal price and customers gained due to increase in quality which decides the final quality outcome, (ii) at the optimal price, the total contribution for the non-OES firm increases monotonically with investment in technology, (iii) the decision for non-OES firm to shift to more capable technology is defined by the threshold of fractional change in demand $(y)$ at the optimal price and fractional increase in fixed cost $(z)$, which is a parabolic curve, (iv) If the fractional change in demand at the optimal price increases at an increasing rate with fractional increase in technology investment then non-OES will choose most capable technology.

We find the following important managerial implications when OES and non-OES enters the market simultaneously, the decisions depend on the risk behavior of supplier: (i) When a new entrant is a pessimist firm, it chooses the worst outcome for itself, specifically when competitor price is too low, (ii) different investment decisions in technology the optimal performance quality choice chosen by the pessimist firm will be different or same, this difference arises because more capable technology decreases the defect rate during the manufacturing process which affects the quantity ofraw material used to produce one component, and (iii) When a new entrant is an optimist firm, it chooses the best outcome, a firm following a maxmax strategy would realize lower than expected demand and hence profit as compared to a situation when it follows a maxmin strategy.

The remaining paper is organized as follows. In section 2, we review the literature related to price and quality competition. We state the modeling assumptions, particularly on cost and demand in section 3. In section 4, we describe and analyze the decision model where nonOES firm makes a product decision. In section 5, we describe and analyze the case where OES and non-OES enter the market simultaneously to make their product decisions, and lastly, in section 6, we provide limitations and conclusions. 


\section{LITERATURE REVIEW}

Shaked and Sutton $(1982,1983)$ first modeled price and quality competition in a two firm environment. But it ignored the effect of quality on cost. Since then plethora of research has been done in the area of quality/service decisions of a firm in the areas of economics, operations management and marketing (Moorthy, 1988, Karmarkar and Pitbladdo, 1997,Banker et al., 1998, Tsay and Agrawal, 2000, Narasimhan and Mendez, 2001, Bernstein and Federgruen, 2004,Paulson Gjerde and Slotnick, 2004, Nair and Narasimhan, 2006, Allon and Federgruen, 2007, Matsubayashi, 2007, André, González, \& Porteiro, 2009, Federgruen \& Yang, 2009, Lacourbe, Loch, \& Kavadias, 2009, Yayla-Küllü et al., 2013).The literature where firms make quality based strategic choices are divided into two, based on the amount of information possessed by consumers (see, e.g., Schwartz and Wilde (1985), Chan and Leland (1982), and Cooper and Ross (1984)) and based on the various preferences of consumers (see, e.g., Besancenot and Vranceanu (2004), Rogerson (1988), and Wolinksy (1983)).Motta (1993) modeled for price and quality competition considering the effect of quality on variable and fixed cost. Thereafter, there has been plenty of work done in this area. Competitive quality choice for remanufactured product as well as new product development has been studied in literature with greatinterest (Orsdemir et al., 2014, Plambeck and Wang 2009, Souza et al. 2004, Fishman and Rob 2000), specifically depending on the order in which competing firms make quality choice, we can classify the literature on price and quality competition into two categories. First, when quality is decided simultaneously by two firms and then observing each other choices of quality, prices are chosen (Motta 1993, Banker et al. 1998, Chambers et al., 2006 and Matsubayashi 2007). Second, when quality is decided sequentially by two firms and then prices are chosen (Choi and Shin 1992 and Grube 1997). These papers primarily focused on determining the price and quality at equilibrium. Shaked and Sutton $(1982,1983)$ concludes that at equilibrium products of the two firms will be differentiated. Similar, results are observed by Tirole (1988) and Motta (1993). In addition, Banker et al. (1998) concludes that higher competition benefits customers in terms of higher product quality. Choi and Shin (1992) and Grube (1997) conclude that the early chooser of quality will operate at higher quality and will earn higher profits.

Andrei and Dubovik (2012) consider an oligopolistic firms that compete for consumers by varying quality and prices of the products, where some consumers have knowledge of quality and prices, a few know about the price, and a few know nether, authors derive equilibrium for these conditions which are characterized by firms involving in a mixed strategy in quality-price space. Chioveanu (2012)stress the importance of price and quality competition that happens simultaneously, quality is assumed as two levels here, and in equilibrium firms must use mixed strategies that randomize both price and quality and thus obtain profits. Karaer and Erhun (2014) study the role of quality as an entry deterrence to a new firm in a monopolistic market, conditions are derived for blocking the new entrant by incumbent, in other words more investment in quality is necessary for the new entrant, or allowing the entrant. Saberi et al., (2014) study price and quality competition among network and content service providers in an internet based service study, the authors achieve equilibrium with varying levels of demand, price and quality. In all aforementioned papers, the decision on price and quality were determined using game theoretic principles.

In modeling quality, most of the papers on price and quality competition considers it as a scalar variable. Economics literature interprets quality as design quality, which supposedly is an amalgamation of performance, reliability, aesthetics and durability (Shaked and Sutton 1983 1982, Motta 1993, Grube 1997). However, in the replacement market quality needs to be interpreted into two forms, that is, performance and conformance quality. We model this quality decision as a vector. Also, quality has been assumed to affect the various components of cost in numerous ways. Variable cost as a function of quality has been modeled by Shaked and Sutton (1983), Motta 1993, Grube 1997, Banker et al. (1998). In addition, papers have also taken the effect of quality on cost only through fixed cost (Motta 1993, Banker et al. 1998). Andrei and Dubovik (2012), Armstrong and Chen (2009) assume quality as an endogenous function of price, based on the simple hypothesis higher price comes at a higher cost. Chioveanu (2012) assume a two level of quality, high and low, and show that equilibrium consumers purchase the one that provides them the best deal. Orsdemir et al., (2014) quality is assumed to be two level, and if the products have similar cost consumer will prefer the product with higher quality. Saberi et al., (2014) consider two and three levels of service quality for the example problems that were considered. Quality in Veldman and Gaalman (2014) is viewed as a combination of design quality and conformance quality. Most of the papers work with the assumption on functional form of cost with respect to quality. Karaer and Erhun (2015) assume quality on the basis of investment made by the firm, higher quality require higher investment and viseversa. Assumptions of linear (Banker et al. 1998) and quadratic effects (Motta 1993) of quality on variable cost are also used. Because of the one-dimensional nature of quality, it has been modeled in the manner such that the cost of production increases with quality. On the other hand, performance quality and conformance quality is seen to affect the cost in different fashion. They have a different impact on the variable and fixed cost components. This has been discussed in detail in section 3.1.

Demand has also been modeled in various ways in the earlier papers. Tirole (1988) uses the additive consumer preference utility function, Shaked and Sutton (1982 1983) uses the multiplicative utility function and Banker et al. (1998) uses the linear demand function motivated by Dixit (1979) to model demand. Here, we extend the demand function used by Banker et.al.(1998) to incorporate the effect of technology choice on demand (as discussed in section 3.2). Also, the earlier demand function was based on the assumption that quality is a continuous variable. In reality, auto component manufacturers have finite and limited options for performance and conformance quality. This requires us to model these product choices as discrete variable as opposed to continuous variable. Modeling it as a continuous variable makes the interpretation of the solution difficult and rounding off a solution to the nearest integer 
could lead to a sub-optimal solution. Lastly, except Baker et al. (1998), which incorporates dissimilarity between competing firms (in the form of their potential to gain customers and absorb fixed cost), none of the papers have considered asymmetry for competing firms. The presence of heterogeneous firms in the replacement market drives us to consider the differences of competing firms while designing the model, both from demand and cost perspective.

\section{MODELING ASSUMPTIONS}

In the first problem, we determine the optimal choices related to performance quality, process technology and price for a non-OES firm. The entry of the non-OES happens in a market where another player (that is, OES) is already present. The non-OES firm launches its product observing the product offering and price of the OES product. The OES firm doesn't react to the competitive threat from non-OES, being an establish firm. These two players are primarily different in their linkages with other industry players, where OES has linkages with OEM and non-OES is an independent player in the market. We model for the optimal product related decisions by non-OES firm in this situation. Our modeling features include, the type and form of our decision variables (described in section 3.1 ), the firm level demand as a function of its decision variables (described in section 3.2) and the nature of the cost function for the non-OES (described in section 3.3). These modeling features still hold when we model for another variant of the above problem where, OES and nonOES firms enter the market together. In this case, both the firms make decisions on product competitively. We determine the optimal choices related to performance quality, process technology and price for non-OES and OES firms.

\subsection{Defining the Decision Variables}

Technology can be defined not only in terms of the equipment's and machines a firm uses, but also the kind of workers on shop floor (skilled/unskilled), design of testing stage and the conformance quality of a product. We use technology to define all these characteristics. For a firm who is deciding to adopt a certain technological setup, often he has limited choices. Considering this, we model the decision of technology as a discrete choice variable. Throughout this paper we use one of the replacement market components, a muffler to show our results.(However, the results and insights can be generalized to most of the other components as well.) Muffler manufacturers can technologically differentiate among themselves during the welding of muffler. There are three kinds of technology choices available to the manufacturers: hand held welding, semi-automated wielding and robotic welding (Sutton 2002). Thus, the technology choice set has three choices $(t \in\{1,2, \ldots, n\}$, $n=3$ ), where 1 indicates lowest capable technology needing lowest investment. The performance quality of a component (that is, its operating characteristics) is usually a function of technology and the raw material. In our modeling, we assume that performance quality has a predominant influence of raw material. Specifically in our example of a muffler, there are two kinds of raw materials: aluminum- coated steel (which leads to lower quality) and ferritic stainless steel (which leads to better quality). Thus, the quality choice set has two choices $(q \in\{1,2, \ldots, m\}, m=2)$ where 1 indicates lower quality muffler. Lastly, price is modeled as a continuous variable, $p \in[0, \infty)$.

\subsection{Demand Function}

Linear demand function (in firm's own price) has been widely used in modeling competitive situations involving price-quality (Banker et al. 1998, Matsubayashi 2007) and only price competition (Eliashberg and Steinberg 1991). We also work with an assumption of linear demand model as first propounded by (Dixit 1979), where the demand for $i$ firm is denoted by $x_{i}$ or $D_{i}\left(p_{i}, p_{j}\right)$ such that

$$
x_{i}=D_{i}\left(p_{i}, p_{j}\right)=\alpha_{i}-\beta_{i} p_{i}+\gamma_{i} p_{j}
$$

Here, $\alpha_{i}$ is firm $i$ 's maximum demand potential when a firm almost offers the product free and competitor prices its product very high, $\boldsymbol{\beta}_{i}$ is change in demand for per unit change in firm's own price, $\gamma_{i}$ is change in demand for per unit change in competitor's price. This demand function is derived using linear utility function. Later, Banker et al. (1998) extends this demand function to incorporate a situation of quality competition, which is given by

$$
x_{i}=D_{i}\left(q_{i}, q_{j}, p_{i}, p_{j}\right)=\alpha_{i}-\beta_{i} p_{i}+\gamma_{i} p_{j}+\delta_{i} q_{i}+\mu_{i} q_{j}
$$

Here, $\delta_{i}$ is change in demand for per unit change in firm's own quality and $\mu_{i}$ is change in demand for per unit change in competitor's quality Besides, demand being a function of price and quality as modeled previously, we extend the demand model to incorporate the discrete quality choice by using the term, $\lambda_{i}\left(q_{i}, q_{j}\right)$. In addition, we add the a term for discrete technology choice of a firm (that is, $\left.\theta_{i}\left(t_{i}, t_{j}\right)\right)$. The demand function used in our model is given by,

$x_{i}=D_{i}\left(t_{i}, t_{j}, q_{i}, q_{j}, p_{i}, p_{j}\right)=\alpha_{i}-\beta_{i} p_{i}+\gamma_{i} p_{j}+\lambda_{i}\left(q_{i}, q_{j}\right)+\theta_{i}\left(t_{i}, t_{j}\right)$

Here, $\alpha_{i}$ is firm $i$ 's demand potential for a given product offering choices when a firm almost offers the product free and competitor prices its product very high, $\lambda_{i}\left(q_{i}, q_{j}\right)$ is a step function which denotes the effect of own and competitor's performance quality on firm's own demand as performance quality is a discrete variable. The increase in $i^{\text {th }}$ firm's own quality causes the market demand to increase for all price points. Similarly, $\theta_{i}\left(t_{i}, t_{j}\right)$ is a step function which denotes the effect of own and competitor's process technology on firm's own demand, as performance quality is a discrete variable. The investment by $i$ firm in higher end technology causes the market demand to increase for all price points.

\subsection{Cost Function}

We assume that the cost to produce an extra unit is constant, which depends on technology and quality. The total cost function for say firm $i$ is given by

$$
C_{i}\left(t_{i}, q_{i}, x_{i}\right)=M C_{i}\left(t_{i}, q_{i}\right) x_{i}+T_{i}\left(t_{i}\right)
$$

The unit cost (that is, $M C_{i}($.$) ) is a function of product$ offering,that is, process technology and performance 
quality. On the other hand, fixed cost is a function of only process technology (that is, $T_{i}\left(t_{i}\right)$ ) and not performance quality. Because as defined earlier, performance quality of a component is influenced by the kind of raw material chosen, which is variable in nature. Higher performance quality component requires superior type of raw material which increases the unit cost such that $M C_{i}\left(t_{i}, 1\right)<M C_{i}\left(t_{i}, 2\right)<\ldots<M C_{i}\left(t_{i}, m\right), \forall t_{i}$ (where $\mathrm{m}=$ 2 for muffler). The unit cost decreases monotonically with investment in process technology, that is, $M C_{i}\left(1, q_{i}\right)>M C_{i}\left(2, q_{i}\right)>\ldots>M C_{i}\left(n, q_{i}\right), \forall q_{i}$ (where $\mathrm{n}=$ 3 for muffler). Higher end technology impacts the unit cost in a positive manner such that there is a decrease in wastage, rejects, rework and labor cost. Moreover, based on our observation, material cost for auto component contributes to $60 \%$ of the total production cost, the savings through wastage and rejects reduces the cost considerably. However, the fixed cost increases monotonically with investment in technology, that is, $T_{i}(1)<T_{i}(2)<\ldots<T_{i}(n)$. As a result, we define $t_{i}=n$, as the most capable technology and $t_{i}=1$ as least capable technology.

\section{DECISION MODEL: Non-OES ENTERS A MARKET WITH AN EXISTING OES FIRM}

The profit function for the non-OES (denoted as $j$ ) entrant follows readily from the foregoing assumptions and can be expressed as:

$$
\begin{aligned}
& \underset{\substack{p_{j} \geq 0 \\
t_{j} \in\{1,2,3\} \\
q_{j} \in\{1,2\}}}{\operatorname{Max}} \pi_{j}\left(t_{j}, q_{j}, p_{j} \mid t_{i}, q_{i}, p_{i}\right) \\
& =\left(p_{j}-M C_{j}\left(t_{j}, q_{j}\right)\right)\left(\alpha_{j}-\beta_{j} p_{j}+\gamma_{j} p_{i}+\lambda_{j}\left(q_{j}, q_{i}\right)+\theta_{j}\left(t_{j}, t_{i}\right)\right)-T_{j}\left(t_{j}\right)
\end{aligned}
$$

To determine the optimal product choices, we first solve for the pricing decision. For a given quality and technology choice, we optimize the profit function to determine the price. Further, incorporating this price in the profit function, we then determine the product related choices.

It may be noted that for given $t_{j} \& q_{j}, \pi_{j}($.$) is$ concave in $p_{j}$ and optimal price is given by

$p_{j}^{*}\left(t_{j}, q_{j} \mid t_{i}, q_{i}, p_{i}\right)=\frac{\alpha_{j}+\gamma_{j} p_{i}+\lambda_{j}\left(q_{j}, q_{i}\right)+\theta_{j}\left(t_{j}, t_{i}\right)}{2 \beta_{j}}+\frac{M C_{j}\left(t_{j}, q_{j}\right)}{2}$

The corresponding demand and profit is given by,

$$
\begin{aligned}
& D_{j}^{*}\left(t_{j}, q_{j} \mid t_{i}, q_{i}, p_{i}\right)= \\
& \frac{\alpha_{j}+\gamma_{j} p_{i}+\lambda_{j}\left(q_{j}, q_{i}\right)+\theta_{j}\left(t_{j}, t_{i}\right)-\beta_{j} M C_{j}\left(t_{j}, q_{j}\right)}{2} \\
& \pi_{j}^{*}\left(t_{j}, q_{j} \mid t_{i}, q_{i}, p_{i}\right)=\frac{\left(D_{j}^{*}\left(t_{j}, q_{j} \mid t_{i}, q_{i}, p_{i}\right)\right)^{2}}{\beta_{j}}-T_{j}\left(t_{j}\right)
\end{aligned}
$$

We now state our results in the form of propositions. (The proofs of the few related propositions are stated in Appendix B).
PROPOSITION 1 (Optimal price and quality): When the non-OES firm chooses higher performance quality, the optimal price of the non-OES product necessarily increases, but the demand at this price doesn't necessarily increases (such that $q_{j}=2$ instead of $q_{j}=1, \forall t_{j}$ ).

One can expect such behavior of price because of the intrinsic nature of quality and its effects on demand for the product as well as cost of production. Better quality not only increases the marginal production cost but also increases the customers' willingness to pay. Hence customers' positive response to better quality gives flexibility to firms to charge more. In essence, support from the interaction of cost and demand side leads to higher pricing. But similar behavior is not observed in case of demand at this increased price. Due to better quality more customers are ready to buy a product. However, higher prices drive-out few customers. So it's the tradeoff between the gain and loss of customers which decides the final outcome in terms of demand. It is expected that for critical components (such as piston rings, brake pads, and clutch plates) which are crucial to the safety of a driver and passengers, the late entrant non-OES will opt for the best performance quality. This behavior is a norm and to sustain, the non-OES prices appropriately to be profitable. Quality might also be an important factor for certain segments of customers, specifically, Institutional buyers and Branded garage owners. Appendix C provides a numerical example.

PROPOSITION 2 (Optimal price and technology): When the non-OES firm chooses higher technology, the demand for the non-OES product increases at the optimal price but the optimal price doesn't necessarily increases (such that, either $t_{j}=3$ instead of $t_{j} \in\{1,2\}$, or $t_{j}=2$ instead of $\left.t_{j}=1, \forall q_{j}\right)$.

Investment in more capable technology has two opposite effects. First it increases the consumers' willingness to pay but it also decreases the marginal production cost. Hence, better response to technological investment by consumers' allows a firm to increase the price but at the same time gain in marginal cost pushes a firm to decrease the price. With more capable technology, the demand at the optimal price increases because more customers are ready to buy products made from more capable technology as well as there is a reduction in marginal cost. In a real market, it is observed that a late entrant non-OES firm (specifically, regional player) don't have access to easy financing and operate at lower end of the technology spectrum, pricing their products lower vs. OES firms products to be profitable. Appendix $\mathbf{C}$ provides a numerical example

PROPOSITION 3 (Optimal technology and contribution): At the optimal price, the total contribution for the non-OES firm increases monotonically with investment in technology,i.e,

$C_{j}^{*}\left(1, q_{j} \mid t_{i}, q_{i}, p_{i}\right)<C_{j}^{*}\left(2, q_{j} \mid t_{i}, q_{i}, p_{i}\right)<C_{j}^{*}\left(3, q_{j} \mid t_{i}, q_{i}, p_{i}\right), \forall q_{j}$ (where $C_{j}^{*}\left(t_{j}, q_{j} \mid t_{i}, q_{i}, p_{i}\right)$ is the total contribution)

Intuitively, one can say that because of increase in investment in technology, demand increases and marginal cost decreases. The combination of these factors results in 
the increase in total contribution. As mentioned in proposition 2 as non-OES firm could preference to choose lower technology, leading to lower contribution, but still making profits due to lower fixed cost. Appendix C provides a numerical example

PROPOSITION 4: The decision for non-OES firm to choose more capable technology is defined by the threshold curve, defined by fractional change in demand $(y)$ at the optimal price and fractional increase in fixed cost $(z)$ where more capable technology is chosen if $(y+1)^{2} \geq c(z+1 / c)$

Where for $j^{\text {th }}$ firm,

$y=\frac{\left(D_{j}^{*}\left(t_{j}, q_{j} \mid t_{i}, q_{i}, p_{i}\right)-D_{j}^{*}\left(t_{j-}, q_{j} \mid t_{i}, q_{i}, p_{i}\right)\right)}{D_{j}^{*}\left(t_{j-}, q_{j} \mid t_{i}, q_{i}, p_{i}\right)}, \quad z=\frac{T_{j}\left(t_{j}\right)-T_{j}\left(t_{j-}\right)}{T_{j}\left(t_{j-}\right)}$

and

$$
c=\frac{T_{j}\left(t_{j-}\right)}{D_{j}^{*}\left(t_{j-}, q_{j} \mid t_{i}, q_{i}, p_{i}\right)\left(p_{j}^{*}\left(t_{j-}, q_{j} \mid t_{i}, q_{i}, p_{i}\right)-M C_{j}\left(t_{j-}, q_{j}\right)\right)},
$$

$\ni t_{j-}$ represents all the lesser capable technology as compared to $t_{j}, \forall q_{j}$

The parabolic curve, that is, $(y+1)^{2} \geq c(z+1 / c)$ is a locus of the minimum fractional increase in demand at the optimal price for all the possible fractional increase in fixed cost at which a firm will be ready to shift to a more capable technology because of higher profits. It demarcates the region of technology choice into two regions as shown in Figure 2.1. Region 1 represents the scenario when a firm continues with lower capable technology and region 2 represents the scenario when more capable technology is chosen. For example, let a firm is operating at lowest capable technology, that is, $t_{j}=1$ then it will be optimal for firm to shift to more capable technology, that is, $t_{j}=2$ (such that the fractional increase in fixed cost increases by $z_{1}$ ) only if the fractional increase in demand is at least $y_{1}$. Appendix C provides a numerical example.

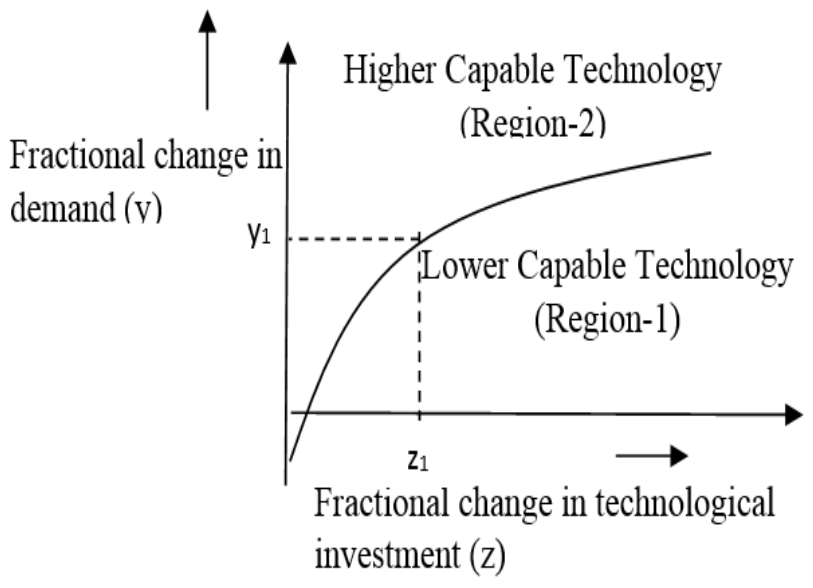

Figure 1 Threshold Path as Generated by Various Market Conditions
PROPOSITION 5: If the fractional change in demand at the optimal price increases at an increasing rate with fractional increase in technology investment then non-OES will choose most capable technology such that $t_{j} \in\{1,2,3\}, \forall q_{j}$.

These results are primarily based on the effect of technological investment on contribution. It is well understood that the contribution increases with increase in technological investment (proposition 3) but it's the relationship between this increase and corresponding increase in fixed cost which primarily affects the technology status of any firm. In essence, this means for every dollar spend on investment of technology if returns increases at a higher rate than firm will opt for more capable technology. Appendix $\mathbf{C}$ provides a numerical example.

PROPOSITION 6 (Reaction by OES):The optimal price, demand and profit decreases for the non-OES firm when OES chooses to invest in more capable technology or chooses to increase the performance quality or does both in light of entry of non-OES firm.

We can interpret this as, when the existing firm decides to reposition the product at higher end of technology or/and quality spectrum then maintaining the status-quo is not an optimal strategy by the late entrant firm. By decreasing price the late entrant can prevent switchover of at least price conscious customers. The effect of change in technology and quality choice of the existing firm has a far more effect on demand than the change in the price of the new entrant. Thus, this leads to overall loss in customers which further translates into loss in profit. This is often a scenario for higher margin components such as axle, springs etc. To counter the loss in demand due to competition, OES launches product variant with improved product features, where non-OES usually doesn't reacts immediately except for price drop. Studying more closely, similar effect on the new entrant's profit and price can be seen when the existing player decides to price high Appendix C provides a numerical example.

\section{GAME THEORETIC MODEL: OES and Non-OES FIRMS ENTER SIMULATANEOUSLY IN A COMPETITIVE SETTING}

We now consider the case where two firms, the OES and the non-OES firms enter the market simultaneously in a competitive setting. In launching a new product, OES and non-OES firms have to make product offering and pricing decisions. After making the entry decision, the OES and non-OES decide on product offering. After knowing each other's decision on product offering, they decide on price. Thereafter, after the entry of firms there is no alteration in price, making the price as a one-time decision. This is true for components with complex supply chain, where changing prices is a difficult proposition for a firm. The motivation of choosing product offering decisions prior to the price is substantiated by the fact that technology choice involves commitment of large investments from a firm and 
decision on quality involves selection of suppliers and fixing of contracts. This scenario is observed when nonOES is a national player, with presence in the international market. Due to prior knowledge and capability this allows them to enter the market along with OES.

This is a challenging situation for firm's as besides their own actions, its profit is also a function of partially unseen competitor actions. This leads them to make decisions based on their understanding of the market and risk appetite. Under two extremes, firms have a tendency to make decisions assuming best and worst case scenarios. We define the best case scenario when a firm maximizes the maximum profit and worst case when a firm minimizes the maximum loss (which is same as maximizing the minimum gain). We term the former as an optimist firm (who adopts Maxmax strategy) and the later as a pessimist firm (who adopts Maxmin strategy). The profit for any firm, say firm $i$, is given by,

$\pi_{i}\left(t_{i}, t_{j}, q_{i}, q_{j}, p_{i}, p_{j}\right)$

$=\left(p_{i}-M C_{i}\left(t_{i}, q_{i}\right)\right)\left(\alpha_{i}-\beta_{i} p_{i}+\gamma_{i} p_{j}+\lambda_{i}\left(q_{i}, q_{j}\right)+\theta_{i}\left(t_{i}, t_{j}\right)\right)-T_{i}\left(t_{i}\right)$

One observes that the profit increases with the increase in price of a competitor. Profit decreases with the investment in higher quality and more capable technology by a competitor. Hence, when an optimist firm decides on $\left(t_{i}, q_{i}\right)$ in the first move, it assumes the best case for itself, that is, competitor operates with least capable technology, lowest quality and very high price $\left(t_{j}=1, q_{j}=1\right.$ and $p_{j}=p_{j}^{u}, \mathrm{u}=$ upper bound of price). But, a pessimist firm assumes the worst case situation, that is, competitor operates with most capable technology, higher quality and negligible price $\left(t_{j}=3, q_{j}=2\right.$ and $\left.p_{j}=\varepsilon\right)$. Since the behavior towards competitive threats cannot be attributed specifically to the size of the player, we solve for all the combinations of strategies by firms for the two competing firms. This is a plausible risk profile scenarios, as OES could choose the maxmax strategy by virtue of its association with OEM and non-OES could choose maxmin strategy by the virtue a strong competition from OES. We study the real market behavior in more depth in Table 1.

Table 1 Risk profile of two categories of entrants and current market scenarios to substantiate the plausibility

\begin{tabular}{|l|l|l|}
\hline \multicolumn{1}{|c|}{ OES risk profile } & \multicolumn{1}{|c|}{ non-OES risk profile } & \multicolumn{1}{c|}{ Situation } \\
\hline Pessimist & Pessimist & $\begin{array}{l}\text { Because of the nature of few components requiring high capital investment (such as axle, } \\
\text { spring leaf) and high margins, the market is set of a fierce competition with non-OES } \\
\text { player being a regional player with credibility from being a supplier in international } \\
\text { markets. }\end{array}$ \\
\hline Pessimist & Optimist & $\begin{array}{l}\text { This situation is seen when non-OES is a regional player and have technical expertise in } \\
\text { making the same part for international market, however OES is a new entrant in the } \\
\text { specific category. }\end{array}$ \\
\hline Optimist & Pessimist & $\begin{array}{l}\text { This situation is seen where non-OES regional player is entering the market, which } \\
\text { realizes the strength of the bigger OES player which is already present. }\end{array}$ \\
\hline & Optimist & $\begin{array}{l}\text { This situation is seen when the part is related to a completely new launch of a car brand. } \\
\text { As the market realizes the uniqueness of the manufacturing process of few parts as well, } \\
\text { both entrants underestimate the competition. }\end{array}$ \\
\hline
\end{tabular}




\subsection{Market at the Post Entry Stage}

\subsubsection{When an Entrant is Pessimist}

Maxmin strategy is adopted by a pessimist firm (say $i$ ) such that it maximizes its minimum profit or minimizes its maximum loss. For such a firm the objective function is given by

$$
\begin{aligned}
& \operatorname{Max}_{\substack{p_{i} \geq 0 \\
t_{i} \in\{, 2,3\} \\
q_{i} \in\{1,2\}}}\left(\operatorname { M i n } _ { \substack { p _ { j } \geq 0 \\
t _ { j } \in \{ 1 , 2 , 3 \} \\
q _ { j } \in \{ 1 , 2 \} } } ( p _ { i } - M C _ { i } ( t _ { i } , q _ { i } ) ) \left(\alpha_{i}-\beta_{i} p_{i}+\gamma_{i} p_{j}\right.\right. \\
& \left.+\lambda_{i}\left(q_{i}, q_{j}\right)+\theta_{i}\left(t_{i}, t_{j}\right)\right)-T_{i}\left(t_{i}\right)
\end{aligned}
$$

PROPOSITION 7: When the two asymmetric OES and non-OES firms enter simultaneously then the optimum price, demand and profit of a pessimist firm (say i) is given by,

$$
\begin{aligned}
& p_{i}^{* \max \min }=R_{i}\left(t_{i}^{*}, t_{j}^{*}, q_{i}^{*}, q_{j}^{*}\right)= \\
& =\frac{\alpha_{i}+\gamma_{i} \varepsilon+\lambda_{i}\left(q_{i}^{*}, q_{j}^{*}\right)+\theta_{i}\left(t_{i}^{*}, t_{j}^{*}\right)+\beta_{i} M C_{i}\left(t_{i}^{*}, q_{i}^{*}\right)}{2 \beta_{i}} \\
& x_{i}^{* \max \min }= \\
& \frac{\alpha_{i}+\lambda_{i}\left(q_{i}^{*}, q_{j}^{*}\right)+\theta_{i}\left(t_{i}^{*}, t_{j}^{*}\right)-\beta_{i} M C_{i}\left(t_{i}^{*}, q_{i}^{*}\right)+\gamma_{i}\left(2 p_{j}^{*}-\varepsilon\right)}{2}
\end{aligned}
$$

$\pi_{i}\left(t_{i}^{*}, t_{j}^{*}, q_{i}^{*}, q_{j}^{*}, p_{i}^{* \max \min }, p_{j}^{*}\right)=$

$\frac{\left(x_{i}^{\max \min }\right)^{2}+\gamma_{i} x_{i}^{\max \min }\left(p_{j}^{*}-\varepsilon\right)}{\beta_{i}}-T_{i}\left(t_{i}^{*}\right)$

where,

Pseudo demand $=$

$$
\begin{aligned}
& x_{i}^{\max \min }=D_{i}\left(t_{i}^{*}, t_{j}^{*}, q_{i}^{*}, q_{j}^{*}\right) \\
& =\frac{\alpha_{i}+\gamma_{i} \varepsilon+\lambda_{i}\left(q_{i}^{*}, q_{j}^{*}\right)+\theta_{i}\left(t_{i}^{*}, t_{j}^{*}\right)-\beta_{i} M C_{i}\left(t_{i}^{*}, q_{i}^{*}\right)}{2}
\end{aligned}
$$

Here we understand the process followed in making pricing decision by a new entrant. Due to the simultaneous nature of entry of two firms, the price of a competitor is unknown. When a new entrant is a pessimist firm, it chooses the worst outcome (that is, when competitor price is too low lets say, it's selling almost free, eta). Another interesting thing to observe is the concept of pseudo demand which a firm expects to realize post entry because of its assumption on the threat from the new competitor. However, there is a mismatch between the demand expected by a new entrant and actual demand because the realized price of a competitor product is different.

PROPOSITION 8: When the two asymmetric OES and non-OES firms enter simultaneously then for the given technology choice, the quality chosen by a pessimist firm (say i) would be,

$$
\begin{aligned}
& q_{i}^{*}=2 \text { if, } \frac{\lambda_{i}(2,2)-\lambda_{i}(1,2)}{\beta_{i}\left(M C_{i}\left(t_{i}, 2\right)-M C_{i}\left(t_{i}, 1\right)\right)}>1 \\
& q_{i}^{*}=1 \text { if, } \frac{\lambda_{i}(2,2)-\lambda_{i}(1,2)}{\beta_{i}\left(M C_{i}\left(t_{i}, 2\right)-M C_{i}\left(t_{i}, 1\right)\right)}<1
\end{aligned}
$$

Else, firm would be indifferent towards higher and lower quality choices

We base these conditions of quality choice as firm's decision on price is a reaction to its decisions on $\left(t_{i}, q_{i}\right)$, firm $i$ uses this price reaction function to decide the $\left(t_{i}, q_{i}\right)$. Also, being a pessimist firm, it chooses the worst outcome (that is, when competitor operates at higher end of technology and quality). Further, equation 10 highlights that for different investment decisions in technology the optimal performance quality choice will be different or same. This difference arises because more capable technology decreases the defect rate during the manufacturing process which affects the quantity of raw material used to produce one component. This effects the marginal production cost such that $M C_{i}(1,2)-M C_{i}(1,1)$ $>M C_{i}(2,2)-M C_{i}(2,1)>M C_{i}(3,2)-M C_{i}(3,1)$.

PROPOSITION 9: When the two asymmetric OES and non-OES firms enter simultaneously then for a given quality choice, the technology chosen by a pessimist firm (say i) would be based on,

$$
\begin{array}{r}
\text { If } 1 / 4 \beta_{i} *\left(\begin{array}{l}
\theta_{i}(3,3)-\theta_{i}\left(t_{i}, 3\right)- \\
\beta_{i}\left(M C_{i}\left(3, q_{i}\right)-M C_{i}\left(t_{i}, q_{i}\right)\right)
\end{array}\right)\left(\begin{array}{l}
\theta_{i}(3,3)+\theta_{i}\left(t_{i}, 3\right)+2 \lambda_{i}\left(q_{i}, 2\right)+2 \alpha_{i} \\
+\gamma_{i} \varepsilon-\beta_{i}\left(M C_{i}\left(3, q_{i}\right)+M C_{i}\left(t_{i}, q_{i}\right)\right)
\end{array}\right) \geq T_{i}(3)-T_{i}\left(t_{i}\right) t_{i} \in\{1,2\} \\
\text { then } t_{i}^{*}=3
\end{array}
$$

It is interesting to see that as the optimal technology choice is a function of quality, nothing specific can be predicted on the behavior of equation 11 with respect to quality. On one hand, the contribution increases for better quality because of enhanced demand that is $\lambda_{i}(2,1)>\lambda_{i}(1,1)$. At the same time contribution could increase or decrease because of change in marginal cost, 
that is, $M C_{i}(2,2)$ could be higher or lesser as compared to $M C_{i}(1,1)$. In essence, by combining conditions from equations 10 and 11 one arrive at the best strategic decisions where the final choices are given by $\left(t_{i}^{*}, q_{i}^{*}, R_{i}\left(t_{i}^{*}, t_{j}^{*}, q_{i}^{*}, q_{j}^{*}\right)\right)=\left(t_{i}^{*}, q_{i}^{*}, p_{i}^{* \max \min }\right)$.

\subsubsection{When an Entrant is Optimist}

Maxmax strategy is adopted by an optimist firm (say $i$ ) who maximizes its maximum profit such that the objective function is given by

$$
\left.\operatorname{Max}_{\substack{p_{i} \geq 0 \\ t_{i} \in\{1,2,3\} \\ q_{i} \in\{1,2\}}} \underset{\substack{\operatorname{Max}_{j} \geq 0 \\ t_{j} \in\{1,2,3\} \\ q_{j} \in\{1,2\}}}{ }\left(p_{i}-M C_{i}\left(t_{i}, q_{i}\right)\right)\left(\alpha_{i}-\beta_{i} p_{i}+\gamma_{i} p_{j}+\lambda_{i}\left(q_{i}, q_{j}\right)+\theta_{i}\left(t_{i}, t_{j}\right)\right)-T_{i}\left(t_{i}\right)\right)
$$

We state few propositions as for a pessimist new entrant. The discussion for the below propositions are identical as for the case above and state the propositions just for completeness.
PROPOSITION 10: When the two asymmetric OES and non-OES firms enter simultaneously then the optimum price, demand and profit of an optimist firm is given by,

$$
\begin{gathered}
p_{i}^{\max \max }=R_{i}\left(t_{i}^{*}, t_{j}^{*}, q_{i}^{*}, q_{j}^{*}\right)=\frac{\alpha_{i}+\gamma_{i} p_{j}^{u}+\lambda_{i}\left(q_{i}^{*}, q_{j}^{*}\right)+\theta_{i}\left(t_{i}^{*}, t_{j}^{*}\right)+\beta_{i} M C_{i}\left(t_{i}^{*}, q_{i}^{*}\right)}{2 \beta_{i}} \\
x_{i}^{*^{*} \max \max }=\frac{\alpha_{i}+\lambda_{i}\left(q_{i}^{*}, q_{j}^{*}\right)+\theta_{i}\left(t_{i}^{*}, t_{j}^{*}\right)-\beta_{i} M C_{i}\left(t_{i}^{*}, q_{i}^{*}\right)+2 \gamma_{i} p_{j}^{*}}{2} \cdot \\
\pi_{i}\left(t^{*}, q^{*}, p_{i}^{{ }^{*} \max \max }, p_{j}^{*}\right)=, \frac{\left(x_{i}^{\max \max }\right)^{2}+\gamma_{i} x_{i}^{\max \max }\left(p_{j}^{*}-p_{j}^{u}\right)}{\beta_{i}}-T_{i}\left(t_{i}^{*}\right)
\end{gathered}
$$

$$
\text { where, pseudo demand }=x_{i}^{\max \max }=\frac{\alpha_{i}+\gamma_{i} p_{j}^{u}+\lambda_{i}\left(q_{i}^{*}, q_{j}^{*}\right)+\theta_{i}\left(t_{i}^{*}, t_{j}^{*}\right)-\beta_{i} M C_{i}\left(t_{i}^{*}, q_{i}^{*}\right)}{2}
$$

When a new entrant is an optimist firm, it chooses the best outcome (that is, when a competitor price is too high, lets say the upper bound on the competitor price is $p_{j}=p_{j}^{u}$ ). As discussed previously, because of mismatch between the expectation by a new entrant on its competitor price and the real price of a competitor, a new entrant realizes different quantum of demand and profit. Intuitively, a firm following a maxmax strategy would realize lower than expected demand and hence profit as compared to a situation when it follows a maxmin strategy.

PROPOSITION 11: When the two asymmetric OES and non-OES firms enter simultaneously then for a given technology choice, the quality chosen by an optimist firm would be based on,

$$
\begin{aligned}
& \text { If } \frac{\lambda_{i}(2,1)-\lambda_{i}(1,1)}{\beta_{i}\left(M C_{i}\left(t_{i}, 2\right)-M C_{i}\left(t_{i}, 1\right)\right)}>1 \text { then } q_{i}^{*}=2, \\
& \text { If } \frac{\lambda_{i}(2,1)-\lambda_{i}(1,1)}{\beta_{i}\left(M C_{i}\left(t_{i}, 2\right)-M C_{i}\left(t_{i}, 1\right)\right)}<1 \\
& \text { then } q_{i}^{*}=1 \text { and else firms are indifferent in choices }
\end{aligned}
$$

Realizing that the firm's decision on price is a reaction to its decision on $(t, q)$, firm $i$ uses this price reaction function to decide the $\left(t_{i}, q_{i}\right)$. Also, being an optimist firm, it chooses the best outcome (that is, when competitor operates at lower end of technology and quality).

$$
\begin{gathered}
1 / 4 \beta_{i} *\left(\theta_{i}(3,1)-\theta_{i}\left(t_{i}, 1\right)-\beta_{i}\left(\begin{array}{l}
M C_{i}\left(3, q_{i}\right) \\
-M C_{i}\left(t_{i}, q_{i}\right)
\end{array}\right)\right)\left(\begin{array}{l}
\theta_{i}(3,1)+\theta_{i}\left(t_{i}, 1\right)+ \\
2 \lambda_{i}\left(q_{i}, 1\right)+2 \alpha_{i}+\gamma_{i} p_{j}^{u} \\
-\beta_{i}\left(M C_{i}\left(3, q_{i}\right)+M C_{i}\left(t_{i}, q_{i}\right)\right)
\end{array}\right) \geq T_{i}(3)-T_{i}\left(t_{i}\right) \\
t_{i} \in\{1,2\} \text { then } t_{i}^{*}=3
\end{gathered}
$$




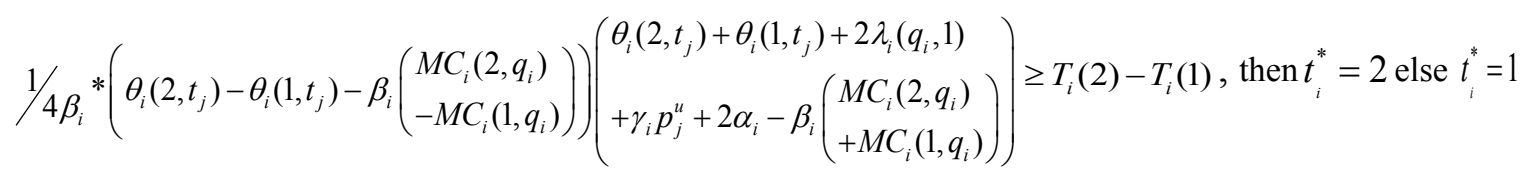

The final choice is given by $\left(t_{i}^{*}, q_{i}^{*}, R_{i}\left(t_{i}^{*}, t_{j}^{*}, q_{i}^{*}, q_{j}^{*}\right)\right)=\left(t_{i}^{*}, q_{i}^{*}, p_{i}^{* \max \max }\right)$.

\section{CONCLUDING REMARKS}

Through this paper, we addressed the issue of a firm who needs to launch a new product in the auto component replacement market. In introducing a new product a firm needs to decide on performance quality, process technology and price. With heterogeneous firms in the replacement market, broadly classified as OES and non-OES, we determine the optimal product offering and pricing decisions under two widely observed competitive situation in Indian auto component replacement market.

Firstly, we model for a situation where the OES firm exists and a late entrant, that is, non-OES enters to launch a product. We prove to show non-OES can demand higher price for better quality product, however better technology choice doesn't necessarily guarantees higher price. NonOES being a late entrant will decide to offer a best quality product only when the loss in customers due to higher prices is compensated by gain in customers due to better quality. In case these two effects balance, non-OES should be indifferent between higher and lower quality. Also, when the non-OES has to decide on technology, it is the relationship between the percentage increase in demand and fixed technological investment which governs the technology decision. Specifically, if the percentage increase in demand has a higher rate than the percentage increase in fixed cost, then a late entrant should opt for a higher end technology. For other relationships between percentage increase in fixed cost and in demand, we define a threshold boundary which segregates high and low technology regions. Analyses of demand at the optimal price reveal, it increases with more capable technology but is indeterminate with better quality. Importantly, post entry we have observed OES usually reacts to the new competition, where to stay in the business non-OES will have to drop the prices.

Next, we model for a situation when the non-OES as well as OES launch their products together. The results indicate that we can have different market configurations depending on multiple factors such as brand perception, negotiation capability with raw material suppliers, distribution reach in the market and prior experience in market. Specifically we show that when OES dominates in marginal cost it is optimal to produce similar or better quality component. When the cost dominance lies with the non-OES firm, the OES product can be of lower quality. This conclusion confirms to the result of the laboratory test, where non-OES components were observed to perform better (Reader 2000). While examining the relative nature of prices, we conclude that non-OES can also price its product higher as compared to OES product. Also, if the non-OES firm has a similar product (with respect to quality and technology) as the OES product, it can price lower. This relationship is primarily influenced by the relative cost structure. We also analyze the sensitivity of these results to different risk behaviors of the firms. Our results show that the above conclusions hold only when either both the entrants are pessimist, optimist or when only one of the entrant (that is the OES) is optimist. When non-OES is optimist and OES is pessimist nothing specific can be concluded.

The current paper has few limitations and could use to extend the paper. Though in the real market, at a steady state we have three categories of suppliers, OES, non-OES national and non-OES regional. We have considered 2 category of players at a time for the two situations. In considering product offering and pricing as a competitive variable, others such as time lag for a late entrant and market spend could be additional next important dimensions. Due to ease of mathematical computations we had used demand function linear in price, which could be extended to non-linear for a OES firm. Though OES firms have lesser price elasticity vs. non-OES beyond a threshold price increase that might not be true. It would be interesting to validate our understanding of the effect of various dimensions of quality on marginal production cost, as it plays a critical role in finally deciding the product. Moreover, validating the results for various functional forms of cost function needs to be studied. Modeling for non-constant marginal cost could be relevant for high volume, highly likely replaced parts such as brake pads, tires.

The situations we have illustrated can be easily used to understand the price dynamics and product choices a new small entrant such as non-OES players can make. Given the complexity of decision making we have seen how they can be profitable and also dominate the market. However, we have learnings for OES, big firms as well. They can capture the market by further improving the performance of their products allowing them to charge premium. This model really fits well to situations where uncertainty is very high and knowledge about the competition is unknown. For auto-parts requiring high capital investments, typically nonOES firm will be risk averse and make reasonable assumptions about the competition. On the other hand, for parts where we have seen non-OES firms who are captive international players and wants to enter in domestic market they might be more prepared to handle the unknowns, making more forthcoming choices.

To summarize key contributions of this paper includes mathematically looking at discrete decisions of quality and technology as an important competitive dimension. This lead us to extend the widely used demand function and cost functions. Next, we model the two widely observed risk behavior of the entrants who have no direct knowledge of competitor choices. Interestingly we do see that these assumptions of the competitor don't necessarily leads to suboptimal decisions. Lastly, we prove that how these real situations complicate the decision process for the firms leading to multiple plausible options. Hence, our paper will enablethe manufactures to ascertain the need for relooking 
at the way decisions are made and automating this process using the proposed decision and game theoretic models.

\section{REFERENCES}

ACMA report 2013-14. Capturing the Global Opportunity. Retrieved June $6^{\text {th }}, 2015$, from www.acmainfo.com

Allon, G., \& Federgruen, A. (2007). Competition in service industries. Operations Research 55(1), pp. 37-55.

André, F. J., González, P., \& Porteiro, N. (2009). Strategic quality competition and the Porter Hypothesis. Journal of Environmental Economics and Management 57(2), pp. 182-194.

Banker, R.D., I.Khosla, K.K. Sinha. (1998). Quality and competition. Management Science 44(9), pp. 11791192.

Bernstein, F., \& Federgruen, A. (2004). A general equilibrium model for industries with price and service competition. Operations Research 52(6), pp. 868-886.

Chambers, C., Kouvelis, P., \& Semple, J. (2006). Qualitybased competition, profitability, and variable costs. Management Science 52(12), pp. 1884-1895.

Chandra, P. and N. Jain. (2009) The Logistics Sector in India: Overview and Challenges in Indian Economic Superpower: Fiction or Future? J.Swaminathan (ed.), World Scientific Press, Singapore, pp. 105-134.

Chester, C., P.Kouvelis, J.Semple. (2006). Quality-based competition, profitability, and variable costs. Management Science 52(12), pp. 1884-1895.

Chioveanu, I. (2012). Price and quality competition. Journal of Economics 107 (1), pp. 23-44.

Choi, C.J.C, H.S. Shin. (1992). A comment on a model of vertical product differentiation. The Journal of Industrial Economics 40(2), pp. 229-231.

Dixit, A. (1979). A model of duopoly suggesting a theory of entry barriers. Bell Journal of Economics 10(1). 2032 .

Dubovik, A., \& Janssen, M. C. (2012). Oligopolistic competition in price and quality. Games and Economic Behavior 75(1), pp. 120-138.

Eliashberg, J., R. Steinberg. (1991). Competitive strategies for two firms with asymmetric production cost structures. Management Science 37(11), pp. 14521473.

Federgruen, A., \& Yang, N. (2009). Competition under generalized attraction models: Applications to quality competition under yield uncertainty. Management science 55(12), pp. 2028-2043.

Garvin, D.A. (1987). Competing on the eight dimensions of quality. Harvard Business Review 65(6), pp. 101-109.

Gjerde, K. A. P., \& Slotnick, S. A. (2004). Quality and reputation: The effects of external and internal factors over time. International Journal of Production Economics 89(1), pp. 1-20.

Grube, U.L. (1997). Strategic choice of quality when quality is costly: the persistence of the high-quality advantage. Rand Journal of Economics 28(2), pp. 372384.

Gruca, T.S., K.R. Kumar, D. Sudharshan. (1992). An equilibrium analysis of defensive response to entry using a coupled response function model. Marketing Science 11(4), pp. 348-358.
Harsanyi, J.C. (1967). Games with incomplete information played by Bayesian players I-III. Management Science 14(3), pp. 159-182.

Hotelling, H. (1929). Stability in Competition. The Economic Journal 39 (153), pp. 41-57.

India Stat. 2015. Auto components report. Retrieved June $6^{\text {th }}, 2015$, from www.indiastat.com.

Juran, J.M. 1951. Juran's Quality Handbook. McGraw-Hill Professional

Karaer, Ö., \& Erhun, F. (2015). Quality and entry deterrence. European Journal of Operational Research 240(1), pp. 292-303.

Karmarkar, U.S., R.C. Pitbladdo.1997. Quality, class and competition. Management Science 43(1), pp. 27-37

Lacourbe, P., Loch, C. H., \& Kavadias, S. (2009). Product Positioning in a Two-Dimensional Market Space. Production and Operations Management 18(3), pp. 315-332.

Lehmann-Grube, U. (1997). Strategic choice of quality when quality is costly: the persistence of the highquality advantage. The RAND Journal of Economics, pp. 372-384.

Make in India. (2015). Automobile Components. Retrieved June $\quad 6^{\text {th }}$, 2015, from http://makeinindia.com/sector/automobilecomponents/.

Matsubayashi, N. (2007). Price and quality competition: The effect of differentiation and vertical integration. European Journal of Operational Research 180(2), pp. 907-921.

Moorthy, K. S. (1988). Product and price competition in a duopoly. Marketing Science 7(2), pp. 141-168.

Motta, M. 1993. Endogenous quality choice: price vs. quality competition. The Journal of industrial Economics 41(2), pp. 113-131.

Nair, A., \& Narasimhan, R. (2006). Dynamics of competing with quality-and advertising-based goodwill. European Journal of Operational Research 175(1), pp. 462-474.

Narasimhan, R., \& Mendez, D. (2001). Strategic aspects of quality: A theoretical analysis. Production and Operations Management 10(4), pp. 514-526.

Nayak, D. (2005). Money for nothing hot sectors to invest in, Economic Times.

Örsdemir, A., Kemahlıŏlu-Ziya, E., \& Parlaktürk, A. K. (2014). Competitive quality choice and remanufacturing. Production and Operations Management 23(1), pp. 48-64.

Rearden, M.W. (2000). OEM or non-OEM automobile replacement parts: the solution to Avery V. State Farm. Florida State University Law Review 28, pp. 542-571.

Saberi, S., Nagurney, A., \& Wolf, T. (2014). A network economic game theory model of a service-oriented Internet with price and quality competition in both content and network provision. Service Science 6(4), pp. 229-250.

Shaked. A. J. Sutton (1982). Relaxing price competition through product competition. Review of Economic Studies 49(1), pp. 3-13.

Shaked. A. J. Sutton (1983). Natural oligopolies. Econometrica 51(5), pp. 1469-83. 
Shivaraman, S., Mathur, M., Klink, G., Kumar, V., Gupta, G. (2015). India's Auto Component Suppliers: New Frontiers in Growth. AT Kearney. Retrieved June $6^{\text {th }}$, 2015, from https://www.atkearney.com/documents/10192/575248 /Indias_Auto_Component_Supplier.pdf/a6fdc363-

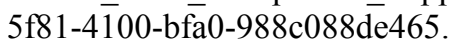

Sutton, J. (2004). The auto component supply chain in China and India- A benchmarking study. Annual Bank Conference on Development Economics.

Tirole, J. (1988). The Theory of Industrial Organization. The MIT Press.

Tsay, A. A., \& Agrawal, N. (2000). Channel dynamics under price and service competition. Manufacturing \& Service Operations Management 2(4), pp. 372-391.
Veldman, J., \& Gaalman, G. (2014). A model of strategic product quality and process improvement incentives. International Journal of Production Economics 149, pp. 202-210.

Vörös, J. (2006). The dynamics of price, quality and productivity improvement decisions. European Journal of Operational Research 170(3), pp. 809-823.

Yayla-Küllü, H. M., Parlaktürk, A. K., \& Swaminathan, J. M. (2013). Multi-Product Quality Competition: Impact of Resource Constraints. Production and Operations Management 22(3), pp. 603-614.

Nimit Jain (Ph.D., Operations and Technology Management) is Head of Data Science with Novartis, FortWorth, Texas. He focuses on applied research by designing algorithms in a Big and messy data environment using state of the art tools and technology such R, Hadoop, Scoop, Apache Drill, HUE. Few areas of his prior work includes supply network design for McDonalds and Proctor \& Gamble, improving customer experience by mining unstructured data for DBS Bank, predictive maintenance of machine equipment in a manufacturing context, process mining for Finance operations. His current area of work includes applying decision sciences for Surgical Equipment Company using network theory and various predictive techniques.

Suman Niranjan (Ph.D., Engineering, Industrial and Human Systems) is an Associate Professor of Operations Management at College of Business Administration-Savannah State University. His research interests lie in inventory control and optimization, supply chain optimization, applied discrete-event simulation, applied Monti Carlo simulation, reverse logistics, multi-variate statistical analysis, cross-cultural research, and entrepreneurship. His research has appeared in journals that include Issues in Decision Sciences, International Journal of Advanced Operations Management, International Journal of Business Performance and Supply Chain Modelling, Journal of Leadership and Organizational Studies, Accounting \& Taxation,Operations and Supply Chain Management, International Entrepreneurship and Management Journal, Margin: The Journal of Applied Economic Researchand Journal of Managerial Issues. 


\section{APPENDIX A}

\section{Relative Demand Parameters and Cost Function}

Demand Parameters:

OES (that is, $i^{\text {th }}$ firm) and non-OES (that is, $j^{\text {th }}$ firm).

$\alpha_{i}>\alpha_{j}$ (OES has higher market potential)

$\left|\frac{\partial x_{i}}{\partial p_{i}}\right|<\left|\frac{\partial x_{j}}{\partial p_{j}}\right|$, that is, $\beta_{i}<\beta_{j}$

(OES haslower variation in demand due to price changes)

$\lambda_{j}\left(q_{i}, q_{j}\right)<\lambda_{i}\left(q_{i}, q_{j}\right) \ni q_{i}=q_{j} \forall q, \lambda_{j}\left(2, q_{i}\right)-\lambda_{j}\left(1, q_{i}\right)<\lambda_{i}\left(2, q_{j}\right)-\lambda_{i}\left(1, q_{j}\right) \ni q_{i}=q_{j} \forall q$

(OEShasbetter demand response to quality)

$\theta_{j}\left(t_{i}, t_{j}\right)<\theta_{i}\left(t_{i}, t_{j}\right) \ni t_{i}=t_{j} \forall t, \theta_{j}\left(2, t_{i}\right)-\theta_{j}\left(1, t_{i}\right)<\theta_{i}\left(2, t_{j}\right)-\theta_{i}\left(1, t_{j}\right) \ni t_{i}=t_{j} \forall t$

(OES has better demand response to technology)

\section{Cost Function}

$M C_{i}\left(t_{i}, 2\right)-M C_{i}\left(t_{i}, 1\right)=M C_{j}\left(t_{j}, 2\right)-M C_{j}\left(t_{j}, 1\right) \ni t_{i}=t_{j} \forall t$

(Similarly decrease in marginal cost due to more capable technology is same for all the firms)

$M C_{i}\left(1, q_{i}\right)-M C_{i}\left(2, q_{i}\right)=M C_{j}\left(1, q_{j}\right)-M C_{j}\left(2, q_{j}\right) \ni q_{i}=q_{j} \forall q$

(This also holds for other technology choices)

$T_{i}(2)-T_{i}(1)=T_{j}(2)-T_{j}(1)$

(increase in fixed cost is same for all the firms and this holds for all technology choices)

\section{APPENDIX B}

\section{Proofs of Various Propositions}

\section{PROOF (PROPOSITION 1):}

$$
\begin{aligned}
& p_{j}^{*}\left(t_{j}, 2 \mid t_{i}, q_{i}, p_{i}\right)-p_{j}^{*}\left(t_{j}, 1 \mid t_{i}, q_{i}, p_{i}\right)=\left(\frac{\alpha_{j}+\gamma_{j} p_{i}+\lambda_{j}\left(2, q_{i}\right)+\theta_{j}\left(t_{j}, t_{i}\right)}{2 \beta_{j}}+\frac{M C_{j}\left(t_{j}, 2\right)}{2}\right)- \\
& \left(\frac{\alpha_{j}+\gamma_{j} p_{i}+\lambda_{j}\left(1, q_{i}\right)+\theta_{j}\left(t_{j}, t_{i}\right)}{2 \beta_{j}}+\frac{M C_{j}\left(t_{j}, 1\right)}{2}\right)=\left(\frac{\lambda_{j}\left(2, q_{i}\right)-\lambda_{j}\left(1, q_{i}\right)}{2 \beta_{j}}+\frac{M C_{j}\left(t_{j}, 2\right)-M C_{j}\left(t_{j}, 1\right)}{2}\right)
\end{aligned}
$$

As $\lambda_{j}\left(2, q_{i}\right)>\lambda_{j}\left(1, q_{i}\right)$ and $M C_{j}\left(t_{j}, 2\right)>M C_{j}\left(t_{j}, 1\right)$, the optimal price necessarily increases with increase in quality. Similarly, difference between demand at the optimal price is given by,

$$
\begin{aligned}
& D_{j}^{*}\left(t_{j}, 2 \mid t_{i}, q_{i}, p_{i}\right)-D_{j}^{*}\left(t_{j}, 1 \mid t_{i}, q_{i}, p_{i}\right)= \\
& \left(\alpha_{j}-\beta_{j} p_{j}^{*}\left(t_{j}, t_{i}, 2, q_{i}, p_{i}\right)+\gamma_{j} p_{i}+\lambda_{j}\left(2, q_{i}\right)+\theta_{j}\left(t_{j}, t_{i}\right)\right)-\left(\alpha_{j}-\beta_{j} p_{j}^{*}\left(t_{j}, t_{i}, 1, q_{i}, p_{i}\right)+\gamma_{j} p_{i}+\lambda_{j}\left(1, q_{i}\right)+\theta_{j}\left(t_{j}, t_{i}\right)\right) \\
& =\frac{\lambda_{j}\left(2, q_{i}\right)-\lambda_{j}\left(1, q_{i}\right)}{2}-\beta_{j}\left(\frac{M C_{j}\left(t_{j}, 2\right)-M C_{j}\left(t_{j}, 1\right)}{2}\right)
\end{aligned}
$$

As $\lambda_{j}\left(2, q_{i}\right)>\lambda_{j}\left(1, q_{i}\right)$ and $M C_{j}\left(t_{j}, 2\right)>M C_{j}\left(t_{j}, 1\right)$, therefore nothing definite can be concluded about the nature of demand at the optimal price. Hence proved.

PROOF (PROPOSITION 2): Without loss of generality, let us see the behavior of optimal price when firm is deciding on most capable technology and next most capable technology, that is, $t_{j}=3$ vis-à-vis $t_{j}=2$,

$$
\begin{aligned}
& p_{j}^{*}\left(3, q_{j} \mid t_{i}, q_{i}, p_{i}\right)-p_{j}^{*}\left(2, q_{j} \mid t_{i}, q_{i}, p_{i}\right)=\left(\frac{\alpha_{j}+\gamma_{j} p_{i}+\lambda_{j}\left(q_{j}, q_{i}\right)+\theta_{j}\left(3, t_{i}\right)}{2 \beta_{j}}+\frac{M C_{j}\left(3, q_{j}\right)}{2}\right)- \\
& \left(\frac{\alpha_{j}+\gamma_{j} p_{i}+\lambda_{j}\left(q_{j}, q_{i}\right)+\theta_{j}\left(2, t_{i}\right)}{2 \beta_{j}}+\frac{M C_{j}\left(2, q_{j}\right)}{2}\right)=
\end{aligned}
$$


$\left(\frac{\theta_{j}\left(3, t_{i}\right)-\theta_{j}\left(2, t_{i}\right)}{2 \beta_{j}}+\frac{M C_{j}\left(3, q_{j}\right)-M C_{j}\left(2, q_{j}\right)}{2}\right)$

As $\theta_{j}\left(3, t_{i}\right)>\theta_{j}\left(2, t_{i}\right)$ and $M C_{j}\left(3, q_{j}\right)<M C_{j}\left(2, q_{j}\right)$, hence nothing definite can be concluded about the direction of change in the optimal price with investment in technology. Similarly, difference between demand at optimal price is given by,

$$
\begin{aligned}
& D_{j}^{*}\left(3, q_{j} \mid t_{i}, q_{i}, p_{i}\right)-D_{j}^{*}\left(2, q_{j} \mid t_{i}, q_{i}, p_{i}\right)= \\
& \left(\alpha_{j}-\beta_{j} p_{j}^{*}\left(t_{j}, 3, q_{j}, q_{i}, p_{i}\right)+\gamma_{j} p_{i}+\lambda_{j}\left(q_{j}, q_{i}\right)+\theta_{j}\left(3, t_{i}\right)\right)-\left(\alpha_{j}-\beta_{j} p_{j}^{*}\left(t_{j}, 2, q_{j}, q_{i}, p_{i}\right)+\gamma_{j} p_{i}+\lambda_{j}\left(q_{j}, q_{i}\right)+\theta_{j}\left(2, t_{i}\right)\right) \\
& =\frac{\theta_{j}\left(3, t_{i}\right)-\theta_{j}\left(2, t_{i}\right)}{2}-\beta_{j}\left(\frac{M C_{j}\left(3, q_{j}\right)-M C_{j}\left(2, q_{j}\right)}{2}\right) .
\end{aligned}
$$

As $\theta_{j}\left(3, t_{i}\right)>\theta_{j}\left(2, t_{i}\right)$ and $M C_{j}\left(3, q_{j}\right)<M C_{j}\left(2, q_{j}\right)$, hence, the demand at the optimal price increases with more capable technology. Hence proved.

\section{PROOF (PROPOSITION 3):}

$$
\begin{aligned}
& C_{j}^{*}\left(2, q_{j} \mid t_{i}, q_{i}, p_{i}\right)-C_{j}^{*}\left(1, q_{j} \mid t_{i}, q_{i}, p_{i}\right)= \\
& \left(p_{j}^{*}\left(2, q_{j} \mid t_{i}, q_{i}, p_{i}\right)-M C_{j}\left(2, q_{j}\right)\right) D_{j}^{*}\left(2, q_{j} \mid t_{i}, q_{i}, p_{i}\right)-\left(p_{j}^{*}\left(1, q_{j} \mid t_{i}, q_{i}, p_{i}\right)-M C_{j}\left(1, q_{j}\right)\right) D_{j}^{*}\left(1, q_{j} \mid t_{i}, q_{i}, p_{i}\right) \\
& =\frac{\left(D_{j}^{*}\left(2, q_{j} \mid t_{i}, q_{i}, p_{i}\right)\right)^{2}}{\beta_{j}}-\frac{\left(D_{j}^{*}\left(1, q_{j} \mid t_{i}, q_{i}, p_{i}\right)\right)^{2}}{\beta_{j}} \\
& =\frac{\left(D_{j}^{*}\left(2, q_{j} \mid t_{i}, q_{i}, p_{i}\right)+D_{j}^{*}\left(1, q_{j} \mid t_{i}, q_{i}, p_{i}\right)\right)\left(D_{j}^{*}\left(2, q_{j} \mid t_{i}, q_{i}, p_{i}\right)-D_{j}^{*}\left(1, q_{j} \mid t_{i}, q_{i}, p_{i}\right)\right)}{\beta_{j}}
\end{aligned}
$$

As $\left(D_{j}^{*}\left(2, q_{j} \mid t_{i}, q_{i}, p_{i}\right)+D_{j}^{*}\left(1, q_{j} \mid t_{i}, q_{i}, p_{i}\right)\right)>0, \quad \beta_{j}>0$ and $\left(D_{j}^{*}\left(2, q_{j} \mid t_{i}, q_{i}, p_{i}\right)-D_{j}^{*}\left(1, q_{j} \mid t_{i}, q_{i}, p_{i}\right)\right)>0$ this indicates that RHS is greater than zero, therefore $C_{j}^{*}\left(2, q_{j} \mid t_{i}, q_{i}, p_{i}\right)-C_{j}^{*}\left(1, q_{j} \mid t_{i}, q_{i}, p_{i}\right)>0$. Hence proved.

\section{PROOF (PROPOSITION 4):}

Without loss of generality,let the decision on technology be between investment in either first or second type of technology. Firm selects $t_{j}=2$ as opposed to $t_{j}=1$ when

$$
\frac{\left(D_{j}^{*}\left(2, q_{j} \mid t_{i}, q_{i}, p_{i}\right)+D_{j}^{*}\left(1, q_{j} \mid t_{i}, q_{i}, p_{i}\right)\right)\left(D_{j}^{*}\left(2, q_{j} \mid t_{i}, q_{i}, p_{i}\right)-D_{j}^{*}\left(1, q_{j} \mid t_{i}, q_{i}, p_{i}\right)\right)}{\beta_{j}} \geq T_{j}(2)-T_{j}(1)
$$

(from profit equation 5)

$$
\begin{aligned}
& \frac{\left(D_{j}^{*}\left(2, q_{j} \mid t_{i}, q_{i}, p_{i}\right)-D_{j}^{*}\left(1, q_{j} \mid t_{i}, q_{i}, p_{i}\right)+2 D_{j}^{*}\left(1, q_{j} \mid t_{i}, q_{i}, p_{i}\right)\right)\left(D_{j}^{*}\left(2, q_{j} \mid t_{i}, q_{i}, p_{i}\right)-D_{j}^{*}\left(1, q_{j} \mid t_{i}, q_{i}, p_{i}\right)\right)}{\beta_{j}} \geq T_{j}(2)-T_{j}(1) \\
& \frac{\left(D_{j}^{*}\left(2, q_{j} \mid t_{i}, q_{i}, p_{i}\right)-D_{j}^{*}\left(1, q_{j} \mid t_{i}, q_{i}, p_{i}\right)\right)}{D_{j}^{*}\left(1, q_{j} \mid t_{i}, q_{i}, p_{i}\right)} D_{j}^{*}\left(1, q_{j} \mid t_{i}, q_{i}, p_{i}\right)\left(\frac{D_{j}^{*}\left(2, q_{j} \mid t_{i}, q_{i}, p_{i}\right)-D_{j}^{*}\left(1, q_{j} \mid t_{i}, q_{i}, p_{i}\right)}{D_{j}^{*}\left(1, q_{j} \mid t_{i}, q_{i}, p_{i}\right)}+2\right) \frac{D_{j}^{*}\left(1, q_{j} \mid t_{i}, q_{i}, p_{i}\right)}{\beta_{j}} \geq \\
& \left(\frac{T_{j}(2)-T_{j}(1)_{1}}{T_{j}(1)}\right) T_{j}(1)
\end{aligned}
$$

(Dividing and multiplying LHS by $\left(D_{j}^{*}\left(1, t_{i}, q_{j}, q_{i}, p_{i}\right)\right)^{2}$ and RHS by $\left.T_{j}(1)\right)$ 
Let $y=\frac{\left(D_{j}^{*}\left(2, q_{j} \mid t_{i}, q_{i}, p_{i}\right)-D_{j}^{*}\left(1, q_{j} \mid t_{i}, q_{i}, p_{i}\right)\right)}{D_{j}^{*}\left(1, q_{j} \mid t_{i}, q_{i}, p_{i}\right)}$ and $z=\frac{T_{j}(2)-T_{j}(1)}{T_{j}(1)}$ such that $y \geq 0, z>0$. Where z represents

the fractional increase in investment and corresponding to this y represents the fractional increase in demand at the optimal price. Also using $D_{j}^{*}\left(1, q_{j} \mid t_{i}, q_{i}, p_{i}\right)=\beta_{j}\left(p_{j}^{*}\left(1, q_{j} \mid t_{i}, q_{i}, p_{i}\right)-M C_{j}\left(1, q_{j}\right)\right)$ the equation transforms to,

$y(y+2) \geq z * \frac{T_{j}(1)}{D_{j}^{*}\left(1, q_{j} \mid t_{i}, q_{i}, p_{i}\right)\left(p_{j}^{*}\left(1, q_{j} \mid t_{i}, q_{i}, p_{i}\right)-M C_{j}\left(1, q_{j}\right)\right)}, y(y+2) \geq c z(\mathrm{c}=$ ratio between break even volume and demand quantity at optimal price). $(y+1)^{2} \geq c(z+1 / c)$. The above equation has a parabolic nature and can be termed as the threshold of technological choice.

\section{PROOF (PROPOSITION 5):}

Following from the theorem 1, we extend the technology threshold for all possible technology choices, $t \in\{1,2,3\}$. The technology threshold for the choice between $\mathrm{t}=1$ and $\mathrm{t}=2$ is given

$(y+1)^{2} \geq c_{1}\left(z+1 / c_{1}\right)$

$\left(\mathrm{c}_{1}=\right.$ ratio between break even volume and demand quantity at optimal price for $\left.\mathrm{t}=1\right)$

Similarly, technology threshold for the choice between $\mathrm{t}=1$ and $\mathrm{t}=3$ is

$(y+1)^{2} \geq c_{2}\left(z+1 / c_{2}\right)$

And, technology threshold for the choice between $\mathrm{t}=2$ and $\mathrm{t}=3$ is

$(y+1)^{2} \geq c_{3}\left(z+1 / c_{3}\right)$

The utility of these curves is to demarcate the feasible space for various technologies and demand change points into two regions, one representing lesser capable technology (that is, region 2) and another more capable technology (that is, region 1). For all technology choice pairs, the region-2 can also be defined by $y \geq c^{*} z$ (as shown in Figure 2.3. In the region above the line $y=c z$, for any technology change (z) the demand change(y) will increase at increasing rate with increase in $\mathrm{z}$. That is the relation between fractional increase in investment and fractional increase in demand is $(y+1)^{\gamma}=c(z+1 / c)$ where $1 \leq \gamma \leq 0$. Hence, one can conclude that firm will adopt more capable technology if the demand increases at increasing rate with increase in investment.

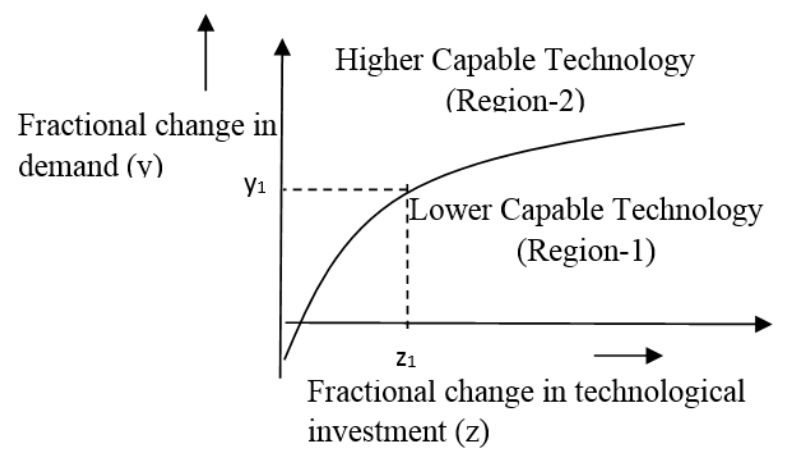

Figure 2 Threshold Paths Shown for all the Technology Choices

PROOF (PROPOSITION 6): We first control the choice of quality by OES and allow for possible shift to more capable technology. Without loss of generality, let this shift in technology be from $t_{i}=2$ to $t_{i}=3$, here the change in price for a new entrant is given by,

$$
\begin{aligned}
& p_{j}^{*}\left(t_{j}, q_{j} \mid 3, q_{i}, p_{i}\right)-p_{j}^{*}\left(t_{j}, q_{j} \mid 2, q_{i}, p_{i}\right)=\left(\frac{\alpha_{j}+\gamma_{j} p_{i}+\lambda_{j}\left(q_{j}, q_{i}\right)+\theta_{j}\left(t_{j}, 3\right)}{2 \beta_{j}}+\frac{M C_{j}\left(t_{j}, q_{j}\right)}{2}\right)- \\
& \left(\frac{\alpha_{j}+\gamma_{j} p_{i}+\lambda_{j}\left(q_{j}, q_{i}\right)+\theta_{j}\left(t_{j}, 2\right)}{2 \beta_{j}}+\frac{M C_{j}\left(t_{j}, q_{j}\right)}{2}\right)=\frac{\theta_{j}\left(t_{j}, 3\right)-\theta_{j}\left(t_{j}, 2\right)}{2 \beta_{j}} \text { (from equation 3) }
\end{aligned}
$$

As $\theta_{j}\left(t_{j}, 3\right)<\theta_{j}\left(t_{j}, 2\right)$, hence, more capable technology of competitor drives down the price of a new entrant. Now, the difference in the demand at this optimal price is given by 


$$
\begin{aligned}
& D_{j}^{*}\left(t_{j}, q_{j} \mid 3, q_{i}, p_{i}\right)-D_{j}^{*}\left(t_{j}, q_{j} \mid 2, q_{i}, p_{i}\right)=\left(\frac{\alpha_{j}+\gamma_{j} p_{i}+\lambda_{j}\left(q_{j}, q_{i}\right)+\theta_{j}\left(t_{j}, 3\right)}{2}-\beta_{j} \frac{M C_{j}\left(t_{j}, q_{j}\right)}{2}\right)- \\
& \left(\frac{\alpha_{j}+\gamma_{j} p_{i}+\lambda_{j}\left(q_{j}, q_{i}\right)+\theta_{j}\left(t_{j}, 2\right)}{2}-\beta_{j} \frac{M C_{j}\left(t_{j}, q_{j}\right)}{2}\right)=\frac{\theta_{j}\left(t_{j}, 3\right)-\theta_{j}\left(t_{j}, 2\right)}{2} \text { (from equation 4) }
\end{aligned}
$$

As $\theta_{j}\left(t_{j}, 3\right)<\theta_{j}\left(t_{j}, 2\right)$, hence there is a decrease in demand at the optimal price as well. And from the profit equation (5) one notices that profit also decreases.

Next, we control the choice of technology by OES and let OES shifts to a higher quality that is, from $q_{i}=1$ to $q_{i}=2$. The difference in the price of a new entrant is given by

$$
\begin{aligned}
& p_{j}^{*}\left(t_{j}, q_{j} \mid t_{i}, 2, p_{i}\right)-p_{j}^{*}\left(t_{j}, q_{j} \mid t_{i}, 1, p_{i}\right)=\left(\frac{\alpha_{j}+\gamma_{j} p_{i}+\lambda_{j}\left(q_{j}, 2\right)+\theta_{j}\left(t_{j}, t_{i}\right)}{2 \beta_{j}}+\frac{M C_{j}\left(t_{j}, q_{j}\right)}{2}\right)- \\
& \left(\frac{\alpha_{j}+\gamma_{j} p_{i}+\lambda_{j}\left(q_{j}, 1\right)+\theta_{j}\left(t_{j}, t_{i}\right)}{2 \beta_{j}}+\frac{M C_{j}\left(t_{j}, q_{j}\right)}{2}\right)=\frac{\lambda_{j}\left(q_{j}, 2\right)-\lambda_{j}\left(q_{j}, 1\right)}{2 \beta_{j}}
\end{aligned}
$$

As $\lambda_{j}\left(t_{j}, 2\right)<\lambda_{j}\left(t_{j}, 1\right)$, hence, better quality of competitor drives down the price of a new entrant. Similarly, analyzing the effect of quality of competitor on demand at optimal price we find that the better quality of competitor drives down the demand at the optimal price. It's easy to observe that even when the competitor shifts to higher quality and more capable technology simultaneously the results on price and demand at optimal price are same for a new entrant. Hence proved.

\section{APPENDIX C}

\section{Numerical Examples to Illustrate Propositions}

Below we show the numerical example to illustrate the applicability of the propositions. To streamline theillustration we have used initial propositions 1, 2, 3 and 6 to showcase how it will work. The logic can be extended with same parameters across propositions.

Case1: - Illustration based on one set of situational parameters.

\begin{tabular}{|l|l|l|}
\hline $\begin{array}{l}\text { Demand } \\
\text { Parameters }\end{array}$ & OES & non-OES \\
\hline alpha & 10 & 10 \\
\hline beta & 4 & 4 \\
\hline gamma & 3 & 3 \\
\hline
\end{tabular}

Non-OES marginal cost: -

\begin{tabular}{|l|l|l|}
\hline$(t, q)$ & quality & \\
\hline technology & 1 & 2 \\
\hline 1 & 40 & 60 \\
\hline 2 & 10 & 15 \\
\hline
\end{tabular}

Fixed cost: -

\begin{tabular}{|l|l|}
\hline$(\mathrm{t})$ & technology \\
\hline 1 & 1000 \\
\hline 2 & 2000 \\
\hline
\end{tabular}

Effect on demand for non-OES different performance quality choices

\begin{tabular}{|l|l|l|l|}
\hline \multirow{4}{*}{ OES } & \multicolumn{3}{|l|}{ non-OES } \\
\cline { 2 - 4 } & & 1 & 2 \\
\cline { 2 - 4 } & 1 & 10 & 20 \\
\cline { 2 - 4 } & 2 & 8 & 16 \\
\hline
\end{tabular}


Effect on demand for non-OES different technology choices

\begin{tabular}{|l|l|l|l|}
\hline \multirow{2}{*}{ OES } & \multicolumn{3}{|l|}{ non-OES } \\
\hline & & 1 & 2 \\
\cline { 2 - 4 } & 1 & 10 & 20 \\
\cline { 2 - 4 } & 2 & 8 & 16 \\
\hline
\end{tabular}

Case 2: - Everything remains same as above, except the demand parameters and marginal cost parameters.

\begin{tabular}{|l|l|l|}
\hline $\begin{array}{l}\text { Demand } \\
\text { parameters }\end{array}$ & OES & $\begin{array}{l}\text { non- } \\
\text { OES }\end{array}$ \\
\hline alpha & 10 & 10 \\
\hline beta & 2 & 2 \\
\hline gamma & 3 & 3 \\
\hline
\end{tabular}

Marginal cost for non-OES

\begin{tabular}{|l|l|l|}
\hline$(\mathrm{t}, \mathrm{q})$ & quality & \\
\hline technology & 1 & 2 \\
\hline 1 & 10 & 12 \\
\hline 2 & 5 & 10 \\
\hline
\end{tabular}

Results to prove proposition 1 , based on case-1 assumptions

The below table, shows the optimal price for non-OES increases with better performance quality,however, the same cannot be said about optimal demand as the results change when the demand parameters change.

\begin{tabular}{|l|l|l|l|l|l|}
\hline \multirow{4}{*}{ Optimal price for non-OES } & \multicolumn{5}{|l|}{ non-OES } \\
\cline { 2 - 6 } & $\mathrm{t}, \mathrm{q}$ & 1,1 & 1,2 & 2,1 & 2,2 \\
\hline \multirow{4}{*}{ non-OES } & 1,1 & 61.25 & 72.5 & 47.5 & 51.25 \\
\cline { 2 - 7 } & 1,2 & 61 & 72 & 47.25 & 50.75 \\
\cline { 2 - 6 } & 2,1 & 61 & 72.25 & 47 & 50.75 \\
\cline { 2 - 6 } & 2,2 & 60.75 & 71.75 & 46.75 & 50.25 \\
\hline
\end{tabular}

Optimal demand decreases with higher performance quality for case-2 choice of parameters

\begin{tabular}{|c|c|c|c|c|c|}
\hline \multirow[b]{2}{*}{ Optimal demand for non-OES } & \multirow[b]{2}{*}{$\mathrm{t}, \mathrm{q}$} & \multicolumn{4}{|c|}{ non-OES } \\
\hline & & 1,1 & 1,2 & 2,1 & 2,2 \\
\hline \multirow[t]{4}{*}{ non-OES } & 1,1 & 85 & 50 & 90 & 55 \\
\hline & 1,2 & 83 & 48 & 89 & 53 \\
\hline & 2,1 & 84 & 49 & 88 & 53 \\
\hline & 2,2 & 83 & 47 & 87 & 51 \\
\hline
\end{tabular}

$\underline{\text { Results based to prove proposition } 1 \text { on case- } 2 \text { assumptions }}$

Optimal price still increases with higher performance quality

\begin{tabular}{|c|c|c|c|c|c|}
\hline \multirow[b]{2}{*}{ Optimal price for non-OES } & \multirow{2}{*}{$\begin{array}{l}\mathrm{t}, \mathrm{q} \\
\mathrm{OES}\end{array}$} & \multicolumn{4}{|c|}{ non-OES } \\
\hline & & 1,1 & 1,2 & 2,1 & 2,2 \\
\hline \multirow{4}{*}{ non-OES } & 1,1 & 87.5 & 91 & 87.5 & 92.5 \\
\hline & 1,2 & 87 & 90 & 87 & 91.5 \\
\hline & 2,1 & 87 & 90.5 & 86.5 & 91.5 \\
\hline & 2,2 & 86.5 & 89.5 & 86 & 90.5 \\
\hline
\end{tabular}


Optimal demand increases with higher performance quality for case- 2 choice of parameters.

\begin{tabular}{|l|l|l|l|l|l|}
\hline \multirow{2}{*}{$\begin{array}{l}\text { Optimal demand for non- } \\
\text { OES }\end{array}$} & \multicolumn{5}{|l|}{ non-OES } \\
\cline { 2 - 6 } non-OES & OES & 1,1 & 1,2 & 2,1 & 2,2 \\
\cline { 2 - 6 } & 1,1 & 155.0 & 158.0 & 160.0 & 163.0 \\
\cline { 2 - 6 } & 1,2 & 153.0 & 156.0 & 159.0 & 161.0 \\
\cline { 2 - 6 } & 2,1 & 154.0 & 157.0 & 158.0 & 161.0 \\
\cline { 2 - 6 } & 2,2 & 153.0 & 155.0 & 157.0 & 159.0 \\
\hline
\end{tabular}

Results to prove proposition 2, based on case-1 assumptions

The below results shows the optimal price for non-OES can decrease or increase when choosing higher technology but optimal demand necessarily doesn't decrease with higher technology.

\begin{tabular}{|c|c|c|c|c|c|}
\hline \multirow[b]{2}{*}{ Optimal price for non-OES } & \multirow[b]{2}{*}{$\mathrm{t}, \mathrm{q}$} & \multicolumn{4}{|c|}{ non-OES } \\
\hline & & 1,1 & 1,2 & 2,1 & 2,2 \\
\hline \multirow{4}{*}{ non-OES } & 1,1 & 61.25 & 72.5 & 47.5 & 51.25 \\
\hline & 1,2 & 61 & 72 & 47.25 & 50.75 \\
\hline & 2,1 & 61 & 72.25 & 47 & 50.75 \\
\hline & 2,2 & 60.75 & 71.75 & 46.75 & 50.25 \\
\hline
\end{tabular}

\begin{tabular}{|l|l|l|l|l|l|}
\hline \multirow{2}{*}{$\begin{array}{l}\text { Optimal demand for non- } \\
\text { OES }\end{array}$} & t,q & non-OES & 1,2 & 2,1 & 2,2 \\
\cline { 2 - 6 } & OES & 1,1 & 50 & 90 & 55 \\
\hline \multirow{4}{*}{ non-OES } & 1,1 & 85 & 48 & 89 & 53 \\
\cline { 2 - 6 } & 1,2 & 83 & 49 & 88 & 53 \\
\cline { 2 - 6 } & 2,1 & 84 & 47 & 87 & 51 \\
\cline { 2 - 6 } & 2,2 & 83 & &
\end{tabular}

Results to prove proposition 2, based on case-2 assumptions

\begin{tabular}{|l|l|l|l|l|l|}
\hline \hline \multirow{2}{*}{$\begin{array}{l}\text { Optimal price for non- } \\
\text { OES }\end{array}$} & t,q & \multicolumn{4}{|l|}{ non-OES } \\
\cline { 2 - 6 } & OES & 1,1 & 1,2 & 2,1 & 2,2 \\
\hline \multirow{4}{*}{ non-OES } & 1,1 & 87.5 & 91 & 87.5 & 92.5 \\
\cline { 2 - 6 } & 1,2 & 87 & 90 & 87 & 91.5 \\
\cline { 2 - 6 } & 2,1 & 87 & 90.5 & 86.5 & 91.5 \\
\cline { 2 - 6 } & 2,2 & 86.5 & 89.5 & 86 & 90.5 \\
\hline
\end{tabular}

\begin{tabular}{|l|l|l|l|l|l|}
\hline \multirow{2}{*}{$\begin{array}{l}\text { Optimal demand for } \\
\text { non-OES }\end{array}$} & t,q & non-OES & \multicolumn{4}{l|}{} \\
\cline { 2 - 6 } & OES & 1,1 & 1,2 & 2,1 & 2,2 \\
\hline \multirow{3}{*}{ non-OES } & 1,1 & 155 & 158 & 160 & 163 \\
\cline { 2 - 6 } & 1,2 & 153 & 156 & 159 & 161 \\
\cline { 2 - 6 } & 2,1 & 154 & 157 & 158 & 161 \\
\cline { 2 - 6 } & 2,2 & 153 & 155 & 157 & 159 \\
\hline
\end{tabular}


Results for proposition 3, where contribution necessarily increases when moving to higher technology choices based on case-1

\begin{tabular}{|c|c|c|c|c|c|}
\hline \multirow{2}{*}{$\begin{array}{l}\text { Optimal contribution for } \\
\text { non-OES }\end{array}$} & \multirow{2}{*}{ t,q } & \multicolumn{4}{|c|}{ non-OES } \\
\hline & & 1,1 & 1,2 & 2,1 & 2,2 \\
\hline \multirow[t]{4}{*}{ non-OES } & 1,1 & 1806 & 625 & 3375 & 1993.75 \\
\hline & 1,2 & 1743 & 576 & 3315 & 1894.75 \\
\hline & 2,1 & 1764 & 600.25 & 3256 & 1894.75 \\
\hline & 2,2 & 1722 & 552.25 & 3197 & 1797.75 \\
\hline
\end{tabular}

Results for proposition 3, where contribution necessarily increases when moving to higher technology choices based on case-2

\begin{tabular}{|l|l|l|l|l|l|}
\hline \multirow{2}{*}{$\begin{array}{l}\text { Optimal contribution for } \\
\text { non-OES }\end{array}$} & t,q & non-OES & \multicolumn{5}{|l|}{} \\
\cline { 2 - 6 } & OES & 1,1 & 1,2 & 2,1 & 2,2 \\
\hline \multirow{3}{*}{ non-OES } & 1,1 & 12013 & 12482 & 13200 & 13447.5 \\
\cline { 2 - 7 } & 1,2 & 11781 & 12168 & 13038 & 13121.5 \\
\cline { 2 - 6 } & 2,1 & 11858 & 12324.5 & 12877 & 13121.5 \\
\cline { 2 - 6 } & 2,2 & 11705 & 12012.5 & 12717 & 12799.5 \\
\hline
\end{tabular}

Results for proposition 6, where if OES moves to higher technology/performance quality, non-OES price, demand and profit falls for case-1.

\begin{tabular}{|c|c|c|c|c|c|}
\hline \multirow[b]{2}{*}{ Optimal price for non-OES } & \multirow[b]{2}{*}{$\mathrm{t}, \mathrm{q}$} & \multicolumn{4}{|c|}{ non-OES } \\
\hline & & 1,1 & 1,2 & 2,1 & 2,2 \\
\hline \multirow{4}{*}{ non-OES } & 1,1 & 61.25 & 72.5 & 47.5 & 51.25 \\
\hline & 1,2 & 61 & 72 & 47.25 & 50.75 \\
\hline & 2,1 & 61 & 72.25 & 47 & 50.75 \\
\hline & 2,2 & 60.75 & 71.75 & 46.75 & 50.25 \\
\hline
\end{tabular}

\begin{tabular}{|c|c|c|c|c|c|}
\hline \multirow{2}{*}{ Optimal demand for non-OES } & \multirow{2}{*}{$\begin{array}{l}\mathrm{t}, \mathrm{q} \\
\mathrm{OES}\end{array}$} & \multicolumn{4}{|c|}{ non-OES } \\
\hline & & 1,1 & 1,2 & 2,1 & 2,2 \\
\hline \multirow{4}{*}{ non-OES } & 1,1 & 85 & 50 & 90 & 55 \\
\hline & 1,2 & 83 & 48 & 89 & 53 \\
\hline & 2,1 & 84 & 49 & 88 & 53 \\
\hline & 2,2 & 83 & 47 & 87 & 51 \\
\hline
\end{tabular}

\begin{tabular}{|l|l|l|l|l|l|}
\hline \multirow{3}{*}{$\begin{array}{l}\text { Optimal profit for } \\
\text { non-OES }\end{array}$} & \multicolumn{1}{|l|}{ non-OES } & \multicolumn{2}{l|}{} \\
\cline { 2 - 6 } & OES & 1,1 & 1,2 & 2,1 & 2,2 \\
\hline \multirow{3}{*}{ non-OES } & 1,1 & 806.25 & -375 & 1375 & -6.25 \\
\cline { 2 - 7 } & 1,2 & 743 & -424 & 1315.25 & -105.25 \\
\cline { 2 - 7 } & 2,1 & 764 & -399.75 & 1256 & -105.25 \\
\cline { 2 - 7 } & 2,2 & 722.25 & -447.75 & 1197.25 & -202.25 \\
\hline
\end{tabular}

